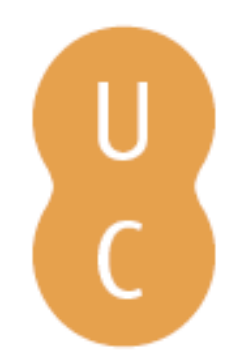

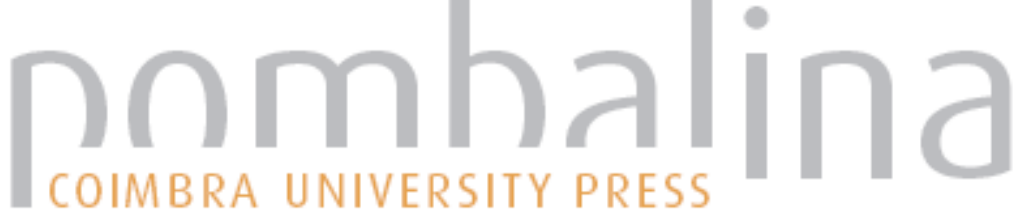

\section{Centro de Interpretação de Muhipiti}

Autor(es): $\quad$ Trindade, Luís; Novela, Milton; Araujo, Renata de

Publicado por: Imprensa da Universidade de Coimbra

URL

persistente: URI:http://hdl.handle.net/10316.2/44319

DOI: $\quad$ DOI:https://doi.org/10.14195/978-989-26-1556-1_14

Accessed : $\quad$ 26-Apr-2023 08:05:53

A navegação consulta e descarregamento dos títulos inseridos nas Bibliotecas Digitais UC Digitalis, UC Pombalina e UC Impactum, pressupõem a aceitação plena e sem reservas dos Termos e Condições de Uso destas Bibliotecas Digitais, disponíveis em https://digitalis.uc.pt/pt-pt/termos.

Conforme exposto nos referidos Termos e Condições de Uso, o descarregamento de títulos de acesso restrito requer uma licença válida de autorização devendo o utilizador aceder ao(s) documento(s) a partir de um endereço de IP da instituição detentora da supramencionada licença.

Ao utilizador é apenas permitido o descarregamento para uso pessoal, pelo que o emprego do(s) título(s) descarregado(s) para outro fim, designadamente comercial, carece de autorização do respetivo autor ou editor da obra.

Na medida em que todas as obras da UC Digitalis se encontram protegidas pelo Código do Direito de Autor e Direitos Conexos e demais legislação aplicável, toda a cópia, parcial ou total, deste documento, nos casos em que é legalmente admitida, deverá conter ou fazer-se acompanhar por este aviso. 


\section{OFICINAS DE \\ MUHIPITI \\ planeamento estratégico \\ património \\ desenvolvimento}

organização:

Walter Rossa

Nuno Lopes

Nuno Simão Gonçalves

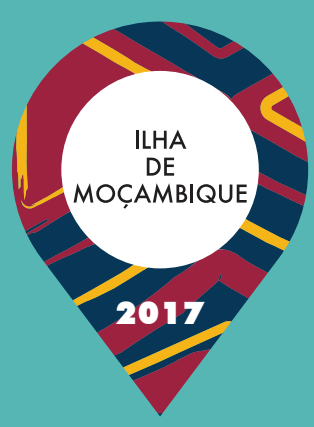




\title{
CENTRO DE INTERPRETAÇÃO DE MUHIPITI
}

\author{
Luísa Trindade \\ Milton Novela \\ Renata de Araujo
}

\section{Missão-encomenda previamente formulada}

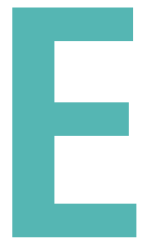

sta oficina tem duas tarefas: a) estruturar e produzir a matriz do que possa vir a ser, no curto e médio prazo os materiais disponibilizados no futuro Centro Interpretativo de Muhipitil Ilha de Moçambique; b) fazer o anteprojeto da respetiva instalação no espaço para tal designado no Conselho Municipal. O objetivo é deixar no local elementos suficientemente detalhados para que a adaptação física do pequeno espaço possa ser iniciada a breve trecho sob orientação da equipa da Universidade Lúrio, e que a equipa da Universidade de Coimbra regresse com dados suficientes para num curto espaço de tempo poder proceder à produção gráfica dos elementos a expor e os envie para montagem. Devem ainda ser produzidas indicações claras para o desenvolvimento deste centro, por exemplo: se não for viável no imediato integrar componentes multimédia, definir o que poderão ser; definir um conjunto prévio de materiais promocionais e de merchandising, bem como a produção ou republicação de álbuns (cartografia, fotografia antiga...), livros (antologias, relatos de viajantes...), etc. Importa registar que as maquetas produzidas para o evento - maqueta da Ilha à escala 1/1000 (1,20m x 3,60m) e maqueta da Fortaleza de São Sebastião à escala 1/200 (1,20m x 1,5m) - deverão ser integradas neste centro. 


\section{En'hipiti nawehaka onira yankani}

En'hipiti nawehaka onira yankani

Nakumbe yulupale

Enukhala mmazini

Wawaka othawene onira mwakó

Enupa zitekié mmalukuni

Molumo khanimaliha ninamuthikilelani

mana ahavotho akina

amiphela wuvanelanani hinhano

watempo ella ninamuvekelani

Mwatthamelale vava zikina

nuthonherani enakalaka mwinizwela

zá n'livuruni massi wohala

orua ti fogo elapo yella nânanupihani 


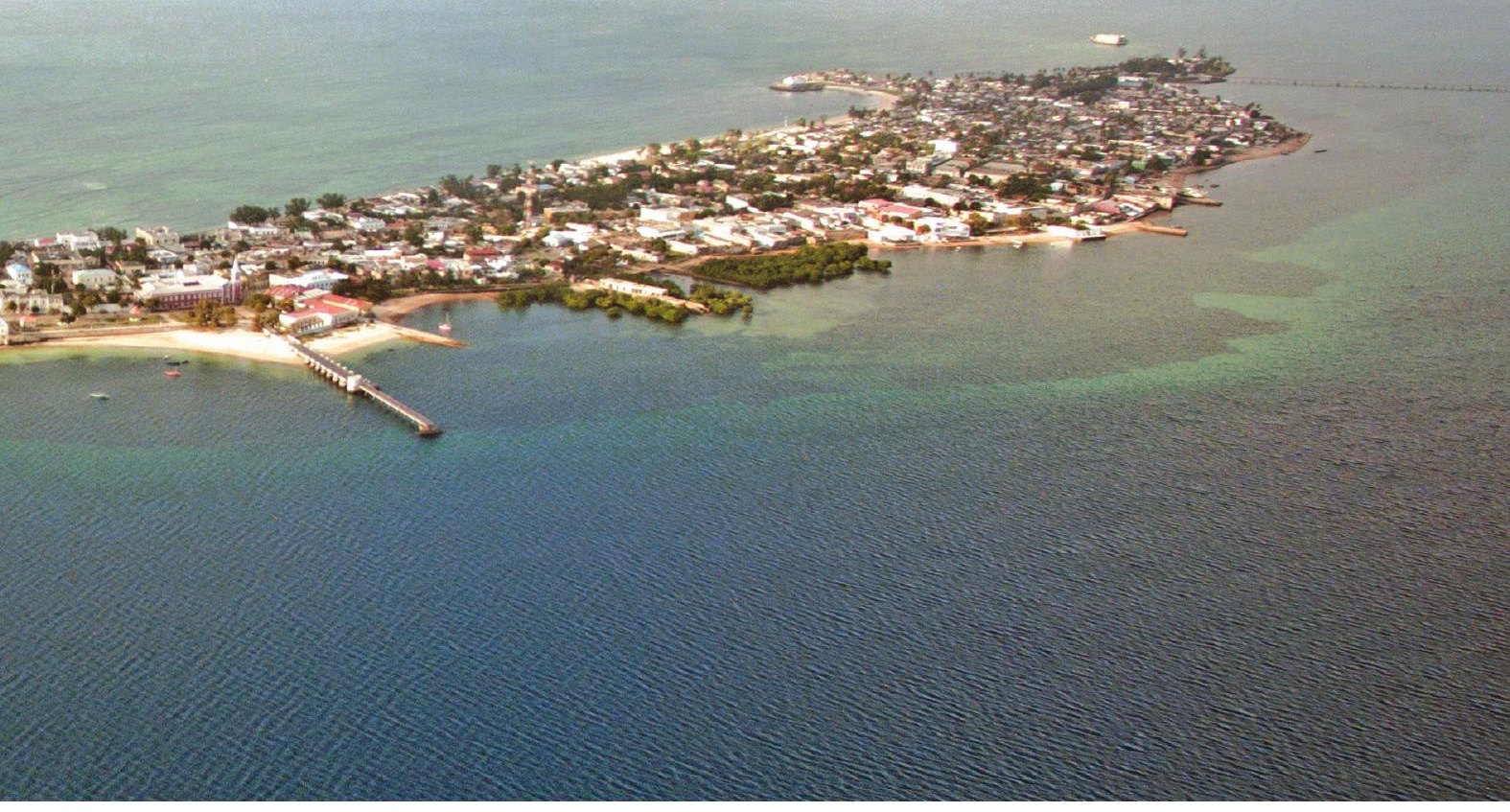

\section{Longe esta ilha parece pequena}

De longe esta ilha parece pequena Esta ilha é grande

Tem longa história desde os habitantes aos seus monumentos Não nos é possível contar-vos tudo quanto temos Pois há outros que querem também falar-vos

Se ainda quereis ouvir algos nossos

Ficais muito tempo nesta llha.

Assim mostrar-vos-iam a rua de fogo Onde vós nunca chegastes

Canção popular macua. Versão livre de Nelson Saúte e António Sopa (1996), publicada na Oceanos, n²5 (p. 127). 
Como bem diz a canção popular, a llha é grande. Não se trata, como é evidente, apenas da distância que se percorre entre a capela do baluarte, numa ponta, e os cemitérios, na outra. Tão pouco é a medida maior do diâmetro que envolve, na terra firme, os territórios adjacentes à baía, que são também partes de um todo, cujo centro é a llha. Os que cantam a canção sabem que, visto de longe, isso tudo pode parecer pequeno. Sabem também que o que é grande é a longa história, que envolve desde os habitantes aos monumentos, e não apenas só estes a falarem sozinhos. Advertem que não é possível contar de uma vez tudo quanto têm para contar, pois há outros que querem também falar. Por isso, perguntam-nos se os queremos ouvir. Esta simples e sábia canção poderia ser o tema musical da nossa experiência no Oficinas. O nosso grupo teve por encomenda a criação de um Centro de Interpretação para a Ilha de Moçambique [CIM]. Cedo percebemos que, antes de fazer qualquer proposta, deveríamos pensar e discutir o próprio conceito.

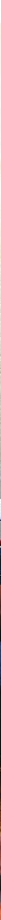


Os Centros de interpretação nasceram na década de 1950, nos Estados Unidos da América, como forma de ajudar a conhecer os grandes parques naturais, cuja escala e diversidade dificultavam a perceção do conjunto. Adaptados a vários fins, os centros de interpretação constituíram-se, no fundo, como a seleção e apresentação de um conjunto de dados que precedia o contacto direto com o objeto, de modo a facilitar a sua leitura.

Formulado pelo norte-americano Freeman Tilden (Tilden:1957; Hicira handbook: 2005), em 1957, na sua obra intitulada Interpreting our heritage, o conceito vem sendo ininterruptamente discutido desde então, existindo um imenso volume de obras produzidas sobre a temática, particularmente no mundo académico anglo-saxónico. O investimento foi definitivamente legitimado quando, em 2008, o ICOMOS ratificou a Carta de Ename, recomendando a interpretação e apresentação como componentes essenciais na conservação e divulgação do património. Profundamente vulgarizado nos últimos anos, o seu número cresce em todo o mundo, sendo usados nas mais diversas situações, de forma tão ampla quanto amplo é hoje o conceito de património. Tudo pode ser e é, de facto, - tratado a partir da figura do centro de interpretação que, assim, se constitui numa parte muito significativa da resposta a esse fenómeno contemporâneo já diagnosticado como doença patrimonial. É, todavia, essa mesma vulgarização que nos obriga a rever criticamente o conceito, aspeto tanto mais importante quanto os seus usos parecem ser genericamente incontestados e a sua filosofia assumida como consolidada.

Não sendo este o local para uma reflexão profunda sobre os problemas que este tipo de dispositivo expositivo encerra (como a tendência para a construção de um discurso unidirecional, tão empobrecido ao nível do conteúdo quanto enriquecido em termos de espetacularidade formal, hoje possibilitada pelos sofisticados meios audiovisuais disponíveis), importa destacar como algumas das suas características podem ser fundamentais na configuração dos mecanismos de descodificação que propomos para a llha.

Desde pelo menos a sua inscrição na Lista do Património Mundial da UNESCO que a llha de passou a ser incluída nos roteiros histórico-culturais do Índico. Como em vários outros casos, o que de certo modo a preservou 

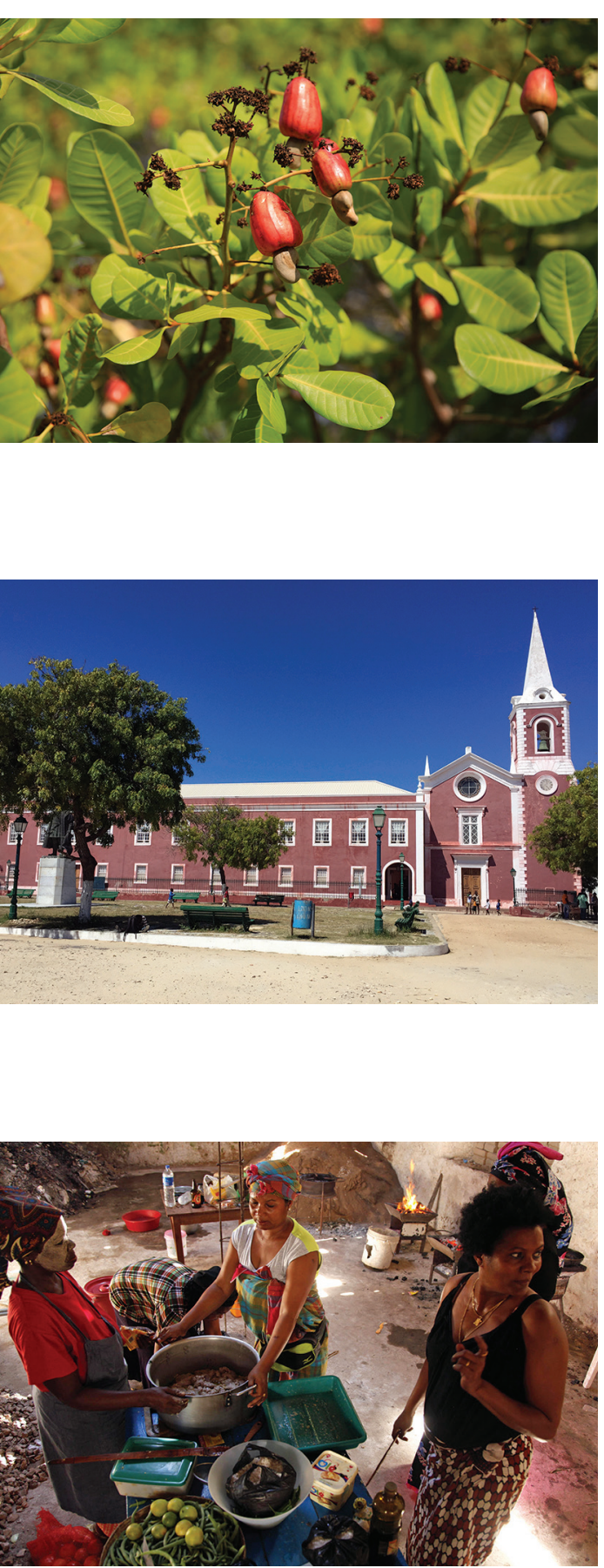

foi o relativo isolamento, vivenciado sobretudo depois da transferência da capital. A llha surge aos olhos dos que a visitam como a imagem de um lugar carregado de memórias que se materializam não apenas nos edifícios, mas também nas comunidades que nela convivem. A perceção e o respeito por todos os aspetos que vinculam a Ilha ao seu passado devem ser tão cruciais quanto os que a mantêm viva, no presente.

Interpretar pressupõe dispor dos dados, no plural e em toda a sua complexidade. Não se trata apenas de adquirir informação, mas de compreender, questionar e, idealmente, reagir. A riqueza e a complexidade da llha e da sua história descortinam um amplo conjunto de temas que vão da arquitetura à botânica, das línguas à gastronomia, das danças aos têxteis. Sem esquecer, evidentemente, as questões mais dolorosas, ligadas ao tráfico de escravos e à escravatura, ao colonialismo e às guerras. Todos os temas exigem ser tratados de forma rigorosa e problematizante. Neste sentido, o que se quer propor não é uma simples montra explicativa para os visitantes, mas um efetivo centro de interpretação da llha e para a llha, que sirva, antes de tudo, aos próprios habitantes.

Mais do que um espaço ou qualquer outro tipo de estrutura 


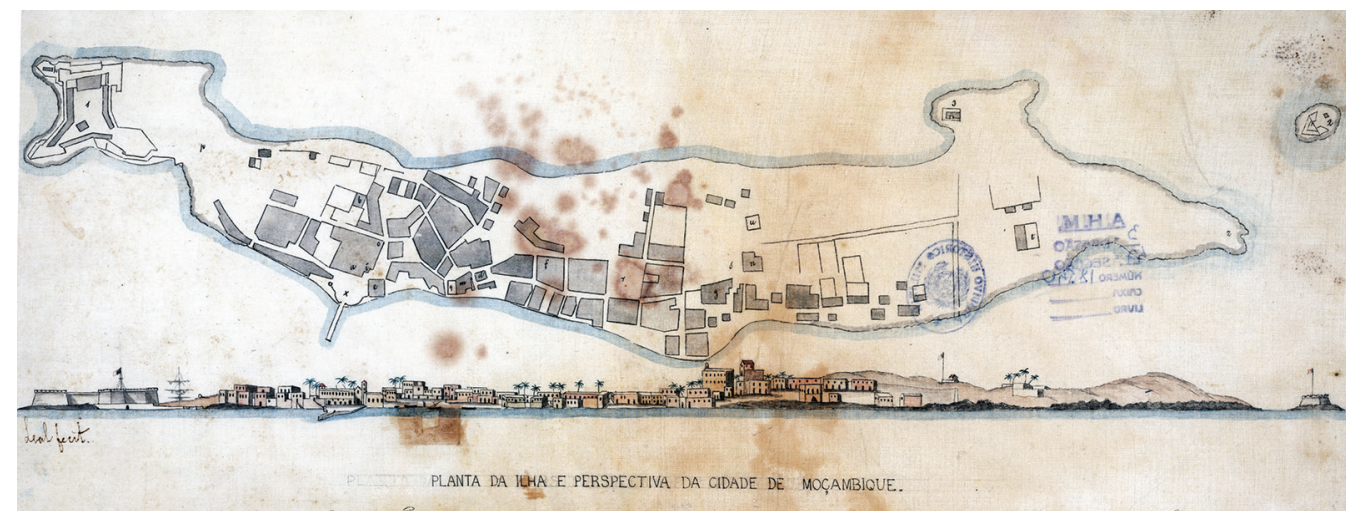

Interpretação deveria ser um grupo de trabalho, plural e dinâmico, cuja base fosse o conhecimento e que imaginamos não só com os estudantes e professores da Universidade Lúrio, mas com a população da própria Ilha e cuja âncora e base propomos que se construa a partir do CEDIM. A missão do CIM é estudar continuamente a llha e o seu território, com o compromisso de envolver a comunidade e devolver-lhe a informação produzida para que ela seja permanentemente discutida e reinterpretada. Um dos objetivos é construir e alimentar em contínuo um conjunto de bases de dados sistematizadas que, num futuro próximo, deverão ser disponibilizadas através de um site e de forma georreferenciada. Numa das bases deverão ser introduzidas informações relativas à bibliografia existente sobre a Ilha, sempre que possível com cópias digitalizadas das publicações cujo acesso seja particularmente difícil. Complementar a esta deverá ser a base de imagens onde se possam recolher cópias digitais, cartografia, iconografia e fotografias relativas à llha. Parte desta recolha de dados já foi iniciada devendo-se dar continuidade ao trabalho de organização e apresentação. Entre outros projetos, prevê-se ainda a criação de um inventário digital, onde se sistematize informações sobre os elementos patrimoniais (materiais e imateriais) da Ilha. Outro dos objetivos do CIM é proporcionar condições para que se possa produzir investigação na própria Ilha, envolvendo não só os alunos e professores da UniLúrio, como também outros investigadores. A partir destas pesquisas, deverá ser organizada uma base de referências e contactos de pessoas fundamentais para o conhecimento dos diversos 
sedimentação de conhecimentos sobre a llha.

Além disso, o CIM pretende que a comunicação de tudo o que for sendo recolhido, tratado e investigado, se faça de forma dinâmica, em exposições, palestras, oficinas, publicações, filmes, etc., que se devem apresentar em diferentes lugares e espaços — desde logo em espaços informais, desde que centrais à própria comunidade — respeitando e integrando os materiais e as possibilidades locais e usando, na sua explicação, as várias línguas que a população fala. Estes são aspetos que consideramos essenciais para que a comunidade se aproprie verdadeiramente do CIM e, assim, se atinja o primeiro dos nossos objetivos.

Na sede, para já no edifício do Conselho Municipal, deverão ficar as maquetes da Ilha e da Fortaleza, assim como mapas com a evolução urbana e outros elementos gráficos e imagens que ajudem a percecionar a materialidade do território e a perceber o papel crucial da Ilha e do contexto mais vasto, como ponto nodal na história das trocas e tensões culturais, comerciais, religiosas e militares do Índico.

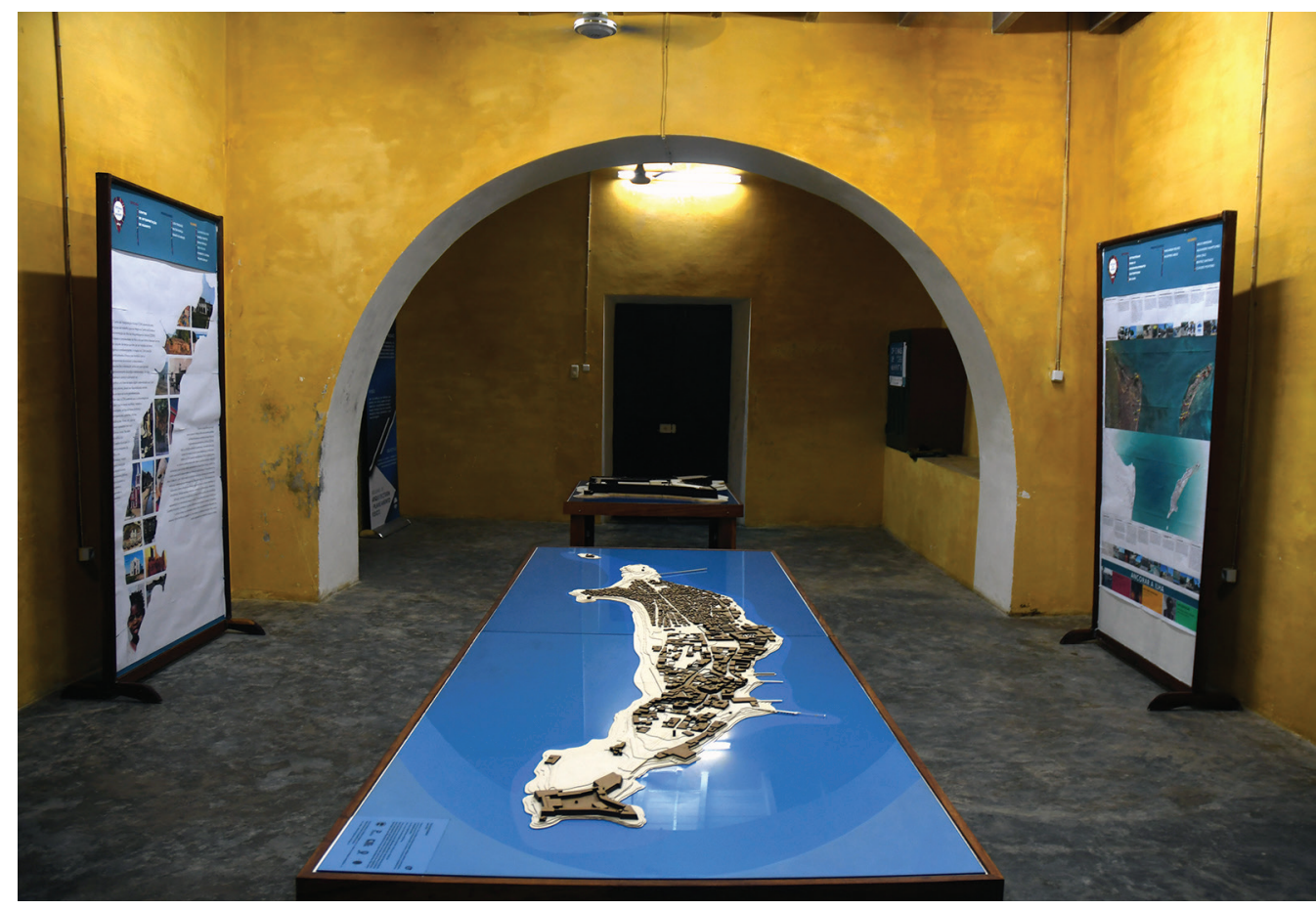


É neste capítulo que o CIM mais se aproxima da configuração tradicional do Centro de Interpretação. Com efeito, o centro interpretativo não tem, por definição, vida própria, apenas se legitimando a partir de uma determinada realidade, seja ela um parque natural, um sítio arqueológico, um centro histórico. Significa isso que se concretiza in situ, atuando em paralelo com o contacto com o(s) espaço(s) cujo conhecimento promove, podendo associar-se igualmente a pequenos troços musealizados, sobretudo nos casos em que a sua preservação é mais urgente. O seu objetivo não é, pois, o de se substituir à realidade, muito pelo contrário: complementa-a, aumentando a qualidade e o potencial da visita. Funciona como elemento polarizador, congregando a informação mais importante para o entendimento do todo, sendo especialmente vocacionado para promover uma leitura global de realidades extensas no espaço e/ou no tempo. É, por isso, especialmente adequado para a descodificação do património urbanístico cuja dimensão, escala e complexidade, tornam a perceção e o entendimento particularmente difíceis.

Ao contrário da experiência que comummente temos quando num museu admiramos um quadro ou uma escultura, a llha e o seu território não se deixam abarcar num único olhar, não permitem que os envolvamos com o nosso próprio movimento, não se deixam ler no seu todo a partir de uma pluralidade de pontos de vista quase simultâneos. Pelo contrário, é a llha e o seu território que nos abarcam. Por isso, as formas de perceção têm que ser necessariamente diferentes. De forma clara, o CIM permite estruturar a informação, recorrendo à exposição cruzada de dispositivos - abstrações, na realidade - que nos auxiliam a ultrapassar as condicionantes próprias deste tipo de património: plantas, maquetas, ortofotomapas, cotejados com outro tipo de materiais como as fotografias antigas e atuais, ou trechos de relatos escritos que permitem perceber a escala, as distâncias e proximidades, a diversidade. São vistas privilegiadas, com efeito, as que este tipo de abstrações proporciona. O seu potencial foi descrito de forma particularmente sugestiva pelos homens dos séculos XV e XVI que, através delas, pensavam ver as cidades e os territórios "como Deus os via" (Ballon e Friedman, 2007: 688). O olhar que, no seu alcance e profundidade, potencia a interpretação, em toda a aceção da palavra. 
Voltando, depois, ao concreto da Ilha, permitem ver as várias cidades nela existentes, a de pedra e cal e a de macuti, desde logo, mas também todas as outras que não têm nome oficial, espaços de transição, por isso especialmente matizados e plurais. Permitem ver o quanto esta llha é grande, como diz a canção que elegemos como tema musical, que também nos convida a ficar muito tempo nesta Ilha. É um convite irrecusável, que o CIM quer continuamente repetir.

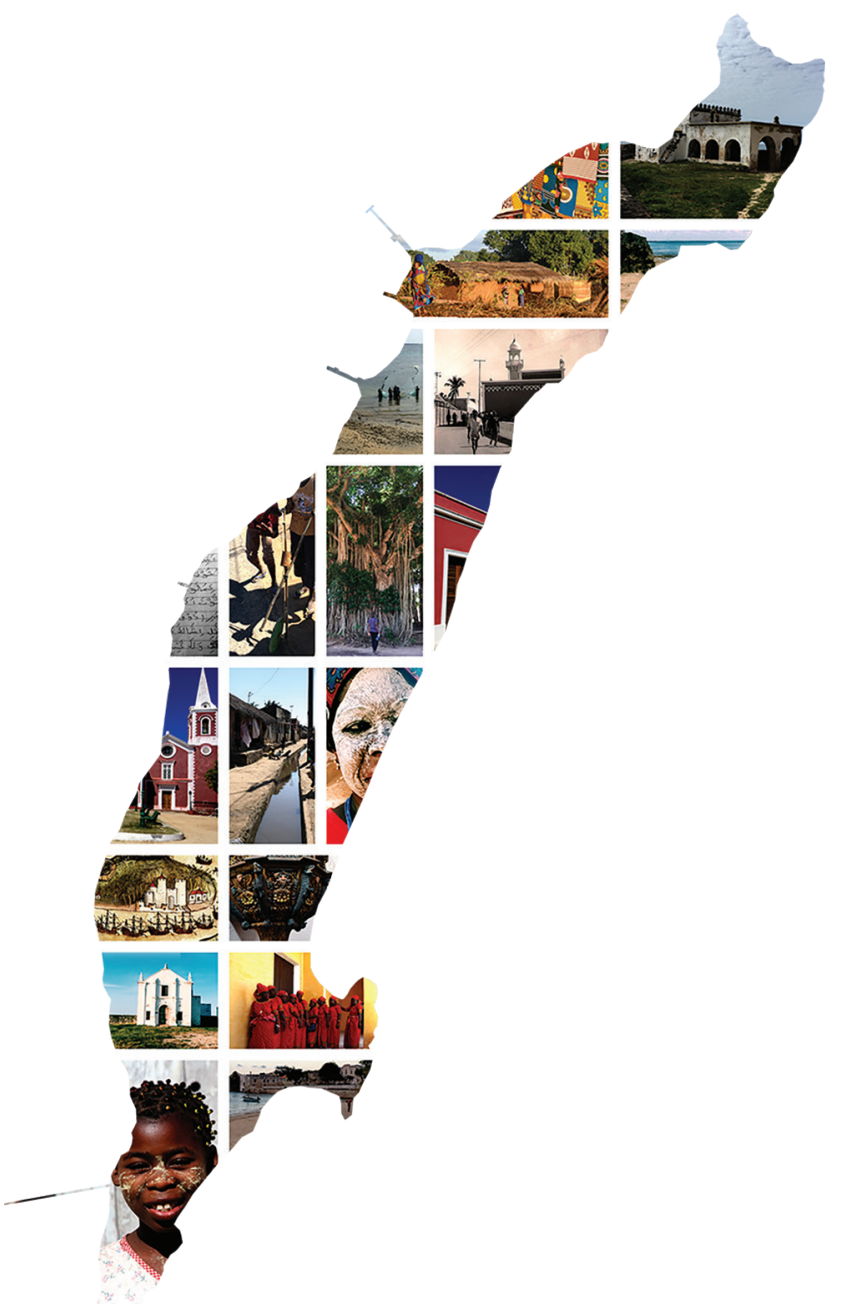




\section{REFERÊNCIAS BIBLIOGRÁFICAS}

BALLON, Hilary; FRIEDMAN, David (2007), "Portraying the City in Early Modern Europe: Measurement, Representation, and Planning", in David Woodward (ed.), Cartography in the European Renaissance. The History of Cartography, 3(1), 688. University of Chicago Press.

HICIRA Project (2005), The Hicira handbook. Heritage Interpretation Centres. Barcelona: Diputació.

ICOMOS (2008), Ename Charter for the interpretation of cultural heritage sites. Paris: ICOMOS.

SAÚTE, Nelson; SOPA, António (1996), "Antologia", Oceanos - Ilha de Moçambique, n 25, Janeiro/Março, 127.

TILDEN, Freeman (1957), Interpreting our heritage: principles and practices for visitor services in parks, museums, and historic places. University of North Carolina Press. 